\title{
Mixed layer depth variability in the Red Sea
}

\author{
Cheriyeri P. Abdulla ${ }^{1}$, Mohammed A. Alsaafani ${ }^{1,2}$, Turki M. Alraddadi ${ }^{1}$, and Alaa M. Albarakati ${ }^{1}$ \\ ${ }^{1}$ Department of Marine Physics, Faculty of Marine Sciences, King Abdulaziz University, Jeddah, Saudi Arabia \\ ${ }^{2}$ Department of Earth \& Environmental Sciences, Faculty of Science, Sana'a University, Yemen
}

Correspondence: Cheriyeri P. Abdulla (acp@stu.kau.edu.sa)

Received: 15 January 2018 - Discussion started: 16 February 2018

Revised: 7 June 2018 - Accepted: 10 June 2018 - Published: 2 July 2018

\begin{abstract}
For the first time, a monthly climatology of mixed layer depth (MLD) in the Red Sea has been derived based on temperature profiles. The general pattern of MLD variability is clearly visible in the Red Sea, with deep MLDs during winter and shallow MLDs during summer. Transitional MLDs have been found during the spring and fall. The northern end of the Red Sea experienced deeper mixing and a higher MLD associated with the winter cooling of the high-saline surface waters. Further, the region north of $19^{\circ} \mathrm{N}$ experienced deep mixed layers, regardless of the season. Wind stress plays a major role in the MLD variability of the southern Red Sea, while net heat flux and evaporation are the dominating factors in the central and northern Red Sea regions. Ocean eddies and Tokar Gap winds significantly alter the MLD structure in the Red Sea. The dynamics associated with the Tokar Gap winds leads to a difference of more than $20 \mathrm{~m}$ in the average MLD between the north and south of the Tokar axis.
\end{abstract}

\section{Introduction}

The surface mixed layer is a striking and universal feature of the open ocean where the turbulence associated with various physical processes leads to the formation of a quasihomogeneous layer with nearly uniform properties. The thickness of this layer, often called the mixed layer depth (MLD), is one of the most important oceanographic parameters, as this layer directly communicates and exchanges energy with the atmosphere and therefore has a strong impact on the distribution of heat (Chen et al., 1994), ocean biology (Polovina et al., 1995), and near-surface acoustic propagation (Sutton et al., 2014). Heat and freshwater exchanges at the air-sea interface and wind stress are the primary forces behind turbulent mixing. The loss of heat and/or freshwater from the ocean surface can weaken the stratification and enhance the mixing. Similarly, a gain in heat and/or freshwater can strengthen the stratification and reduce the mixing. The shear and stirring generated by the wind stress enhance the vertical mixing and play a major role in controlling the deepening of the oceanic mixed layer. Further, the stirring associated with turbulent eddies predominantly changes the mixing process, mainly along the isopycnal surfaces where stirring may occur with minimum energy (de Boyer Montegut et al., 2004; Hausmann et al., 2017; Kara et al., 2003).

The Red Sea is an important intermediate water formation region in the world ocean. Red Sea Outflow Water (RSOW), formed mainly due to open ocean convection in the northern Red Sea (Sofianos and Johns, 2002), propagates through Bab-el-Mandeb to the Gulf of Aden (Alsaafani and Shenoi, 2007) and later spreads to the Indian Ocean. Its signature reaches into the south Indian Ocean about $6000 \mathrm{~km}$ away from the source (Beal et al., 2000). The Red Sea is surrounded by extremely hot arid lands and has a relatively strong evaporation rate $\left(2 \mathrm{~m} \mathrm{yr}^{-1}\right)$ with nearly zero precipitation (Albarakati and Ahmad, 2013; Bower and Farrar, 2015; Sofianos et al., 2002). This region experiences strong seasonality in its atmospheric forcing and buoyancy. These characteristics, along with the lack of river input, make the Red Sea one of the hottest and most saline ocean basins in the world. The narrow and semi-enclosed nature of the basin, the presence of multiple eddies, strong evaporation, lack of river input, very weak precipitation, and seasonally reversing winds, etc. lead to complex dynamical processes in the Red Sea (Aboobacker et al., 2016; Yao et al., 2014a, b; Zhai and Bower, 2013; Zhan et al., 2014).

The increase in number temperature and salinity profiles in recent years enhanced the study of MLD structure and its variability, both globally (de Boyer Montegut et al., 2004; 
Kara et al., 2003; Lorbacher et al., 2006) and regionally (Abdulla et al., 2016; D’Ortenzio et al., 2005; Keerthi et al., 2012, 2016; Zeng and Wang, 2017). The Red Sea has been investigated for many years with an emphasis on its different physical features, but there has been no detailed investigation on MLD variability apart from a few studies addressing the hydrography and vertical mixing of localized areas (Alsaafani and Shenoi, 2004; Bower and Farrar, 2015; Carlson et al., 2014; Yao et al., 2014b).

In this work, an MLD climatology is produced for the first time based on in situ observations. Further, the roles of atmospheric forces and oceanic eddies on the changes in the MLD have been investigated. The sections are arranged as follows: Sect. 2 describes the datasets used and the methodology. The subsequent sections discuss the observed MLD variability in the Red Sea, the role of the major forces on the MLD variability, and the influence of Tokar Gap winds. The main conclusions of the present work are given in the final section.

\section{Data and methods}

\subsection{Datasets}

Temperature and salinity profiles from different sources are collected, which are measured using CTD (conductivitytemperature-density profiler), PFL (autonomous profiling floats including ARGO floats), XBT (expendable bathythermograph), and MBT (mechanical bathythermograph). The World Ocean Database (https://www.nodc.noaa.gov/OC5/ SELECT/dbsearch/dbsearch.html, last access: 1 February 2017) is the main source. Apart from this, data from the CORIOLIS data center (http://www.coriolis.eu.org/ Data-Products/Data-Delivery/Data-selection, last access: 1 February 2017) and several cruises conducted by individual institutions are also used in this analysis. The bathythermograph profiles were depth corrected based on Cheng et al. (2014). A total of 13891 temperature profiles were made for the Red Sea (approximately 14\% of these profiles have salinity measurements) from 1934 to 2017.

These profiles are quality checked according to the procedure given in Boyer and Levitus (1994). In the duplicate check, all the profiles within a $1 \mathrm{~km}$ radius and taken on the same day are considered duplicates and are removed from the main dataset. The levels in the profile with large inversions in temperature (inversion $\geq 0.3{ }^{\circ} \mathrm{C}$ ) are flagged and removed. If three or more inversions are present, then the entire profile is removed. The levels with extreme gradients $\geq 0.7^{\circ} \mathrm{C}$ are also removed from the profile. Since the present work is more focused on the changes in the upper layer of the ocean (from the surface to a $150 \mathrm{~m}$ depth), profiles with low resolutions in the upper layers are removed. Almost $50 \%$ of the profiles have resolutions of $<5 \mathrm{~m}$, while $7 \%$ of the profiles have poor resolutions (resolutions of $>25 \mathrm{~m}$ ).

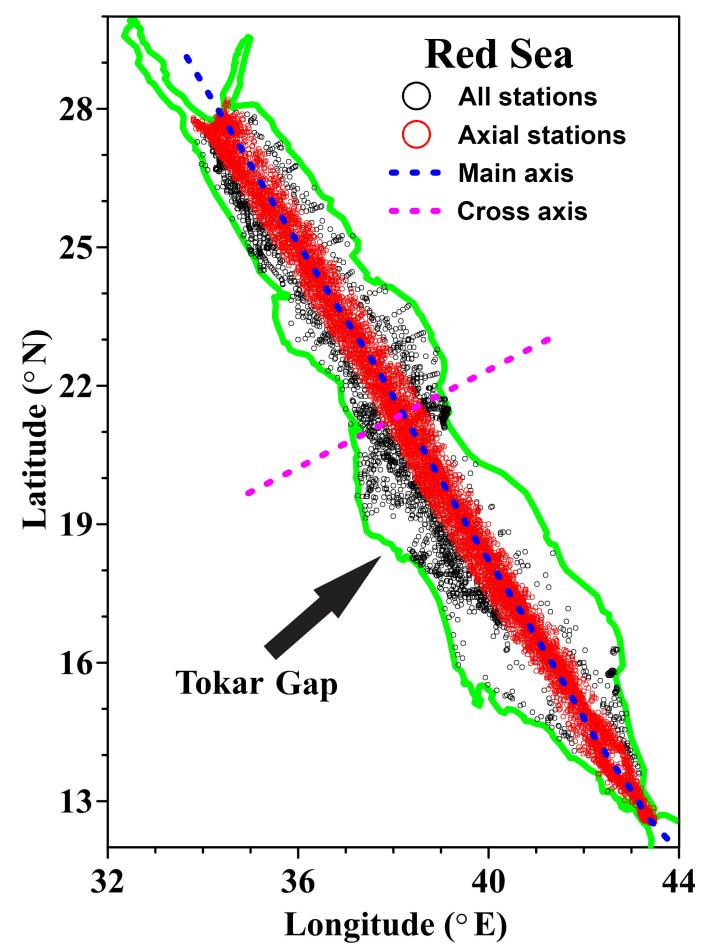

Figure 1. The locations of temperature profiles in the Red Sea. Black circles denote all available profiles, while red circles denote the profiles close to the main axis that are used for climatology calculation. The blue (magenta) dashed line indicates the main axis (cross axis) of the Red Sea.

Out of the total 13891 profiles analyzed, 11212 profiles passed the quality check from CTD (690), PFL (1385), XBT (5507), and MBT (3630), and the spread is shown in Fig. 1. More than $80 \%$ of these profiles are positioned along the middle of the Red Sea, with a sufficient number of profiles for each month (Fig. S1 in the Supplement). The yearly and monthly distributions of the temperature profiles lie along the middle of the Red Sea and are given in the Supplement (Figs. S2-S3). As part of the quality check, 2679 profiles were removed from the main dataset. A total of 2063 salinity profiles are available for the entire Red Sea (Fig. S4 in the Supplement). MLD is estimated based on the temperature profiles due to the increased number and sufficient monthly coverage compared to that of salinity. The distribution of the temperature profiles used in this analysis is shown in Fig. 1.

The monthly mean values of heat fluxes and wind stress data are provided by TropFlux at a $1^{\circ} \times 1^{\circ}$ spatial resolution for the period 1979-2016, which are used to check the influence on MLD variability (http://www.incois.gov. in/tropflux_datasets/data/monthly/, last access: 1 February 2017). TropFlux captures better variability and less bias than the other available fluxes and wind stress products (Praveen Kumar et al., 2012, 2013). Since evaporation is not provided by TropFlux, the monthly mean values of evaporation from OAFlux (from 1979 to 2016 and $1^{\circ} \times 1^{\circ}$ spatial reso- 
lution) are used (ftp://ftp.whoi.edu/pub/science/oaflux/data v3/monthly/evaporation/, last access: 1 February 2017). The TRMM (Tropical Rainfall Measuring Mission; https://pmm. nasa.gov/data-access/downloads/trmm, last access: 1 February 2017) satellite provided the precipitation information for every $0.25^{\circ} \times 0.25^{\circ}$ grid on a 3-hourly to monthly timescale from 1997 to 2016 (TRMM monthly 3B43_V7 product is used). Monthly climatology of heat flux, evaporation, precipitation, and wind stress are calculated. The period of precipitation data used for climatology calculation is shorter than other parameters. The present analysis is focused on the seasonal timescale, and therefore a shorter data period will not significantly affect the results.

The daily sea level anomaly (SLA) maps are provided by AVISO (www.aviso.oceanobs.com, last access: 1 February 2017). These data are the merged product of satellite estimates from TOPEX/Poseidon, Jason-1, ERS-1/2, and Envisat and are globally available with spatial resolution of $0.25^{\circ} \times 0.25^{\circ}$ from the year 1992 to present (Ducet et al., 2000; LaTraon and Dibarboure, 1999). The SLA maps are used to describe the eddy distribution in the Red Sea. The merged data from all satellite estimates provide a general picture of SLA variability and the eddy distribution in the Red Sea, even though the number of satellite tracks passing through narrow regions like the Red Sea is relatively lower than the major ocean basins. Climate Forecast System Reanalysis (CFSR; https://rda.ucar.edu/datasets/ds093. 1/\#!access, last access: 1 February 2017) provided an hourly wind product from 1979 to 2010 at a grid resolution of $0.312^{\circ} \times 0.312^{\circ}$ (Saha et al., 2010), which is validated in the Red Sea (Aboobacker et al., 2016; Shanas et al., 2017). CFSR hourly wind at $10 \mathrm{~m}$ above the surface is used to study the Tokar Gap winds.

\subsection{Methods}

The MLD can be estimated based on different methods. Figure 2 shows a sample temperature profile collected on 19 January 2015 from the Red Sea $\left(24.9^{\circ} \mathrm{N}, 35.18^{\circ} \mathrm{E}\right)$, with short-range gradients within the mixed layer. This gradient could rise from instrumental errors or turbulence in the upper layer. The curvature method (Lorbacher et al., 2006) identified MLD at $32 \mathrm{~m}$ due to the presence of a short-range gradient at this depth. The threshold method (de Boyer Montegut et al., 2004) detected the MLD at $130 \mathrm{~m}$ (threshold $=0.2^{\circ} \mathrm{C}$ ), while the segment method (Abdulla et al., 2016) identified the MLD at $120 \mathrm{~m}$. The segment-method-based MLD could be considered as a reliable estimate compared to both the curvature (underestimation) and threshold method (overestimation). The segment method first identifies the portion of the profile with significant inhomogeneity where the transition from a homogeneous layer to an inhomogeneous layer occurs. Then, this portion of the profile is analyzed to determine the MLD (a detailed procedure of the estimation technique is given Abdulla et al., 2016). In the present study, MLD is es-

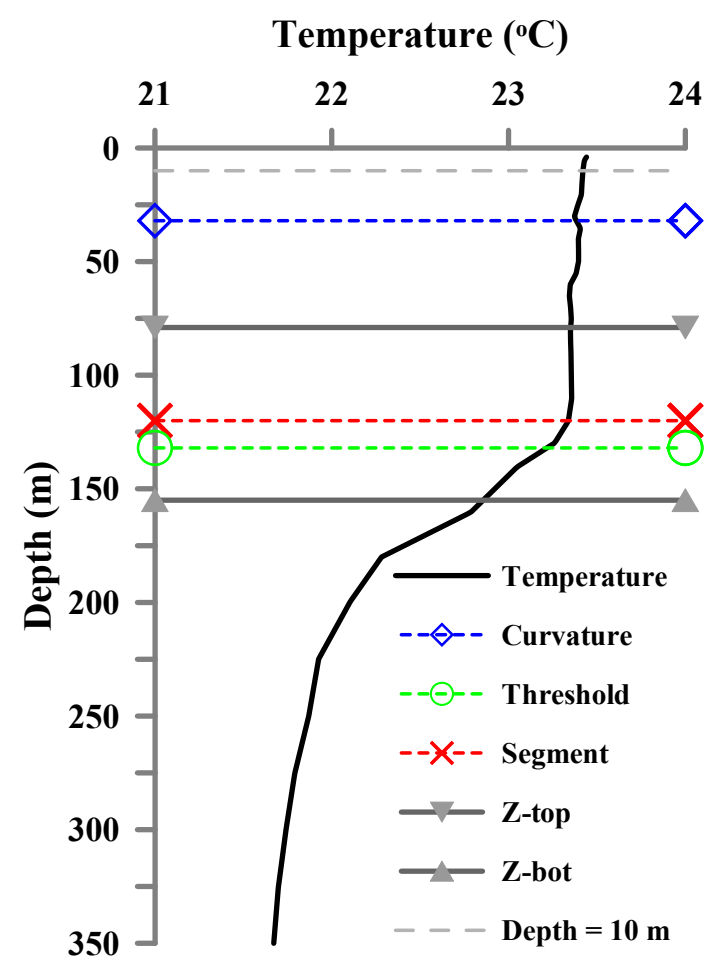

Figure 2. The MLD estimated for a sample temperature profile based on curvature, threshold, and segment methods. The Z-top and Z-bot respectively represent the top and bottom ends of the portion of the profile with significant inhomogeneity.

timated based on the segment method, which is found to be less sensitive to short-range disturbances within the mixed layer (Abdulla et al., 2016).

The availability of profiles is denser along the middle of the Red Sea during all months. The present analysis is performed for the profiles that fall within $0.5^{\circ}$ to the east and west of the main axis that, running along almost the middle of the Red Sea (hereafter called the "main axis"), has the advantage of a sufficient number of profiles for every month. The main axis of the Red Sea is inclined to the west, with respect to true north, by $\sim 30^{\circ}$. For this reason, instead of zonally averaging, the climatology is calculated by averaging the MLDs in an inclined direction parallel to the "cross axis" (Fig. 1). The MLD is estimated for the individual profiles, and then the monthly climatology is calculated every $0.5^{\circ}$ from south to north ( 13 to $\left.27.5^{\circ} \mathrm{N}\right)$.

The heat flux, evaporation, precipitation, and wind stress are interpolated to a $0.5^{\circ} \times 0.5^{\circ}$ spatial grid to match the MLD climatology with the help of the climate data operator (CDO) tool available at http://www.mpimet.mpg.de/cdo (last access: 1 February 2017). The change in surface water 
buoyancy forces is calculated following Turner (1973):

$$
\begin{aligned}
B_{0} & =\left(C_{p}^{-1} g \propto \rho_{0}^{-1} Q_{\text {net }}\right)+(-1 \cdot g \beta s(E-P)) \\
& =B_{0 \mathrm{~T}}+B_{0 \mathrm{H}},
\end{aligned}
$$

where $C_{p}$ is water heat capacity, $g$ is the acceleration due to gravity, $\propto$ is the thermal expansion coefficient, $\rho_{o}$ is the density of surface water, $Q_{\text {net }}$ is the net heat flux at the sea surface, $\beta$ is the haline contraction coefficient, $s$ is the salinity of surface water, $E$ is the evaporation rate, and $P$ is precipitation. In Eq. (1), $\mathrm{B}_{0 \mathrm{~T}}$ and $\mathrm{B}_{0 \mathrm{H}}$ respectively represent the thermal and haline components of the buoyancy force. For ease of explanation, the Red Sea is divided into southern $\left(13-18^{\circ} \mathrm{N}\right)$, central $\left(18-23^{\circ} \mathrm{N}\right)$, and northern $\left(23-28^{\circ} \mathrm{N}\right)$ regions and the seasons are defined as winter (DecemberFebruary), spring (March-April), summer (May-August), and fall (September-November).

\section{Results and discussion}

\subsection{MLD variability in the Red Sea}

The Red Sea exhibits strong seasonal changes in its MLD, with deeper mixed layers during the winter and shallower ones during the summer and gradual changes from deeper to shallower and vice versa in the transitional months. A Hovmöller diagram of the monthly MLD climatology is presented in Fig. 3. The deepest MLD is observed in February and the shallowest during May-June. Significant annual variability is observed in the Red Sea. The maximum value of climatological mean MLD is observed in February in the northern Red Sea, while the minimum occurs at various instances, especially during summer months. The MLD of individual profiles in the northern Red Sea has a wide range of values from 40 to $120 \mathrm{~m}$, mainly due to the presence of an active convection process, while some of the profiles show an MLD deeper than $150 \mathrm{~m}$, consistent with Yao et al. (2014b).

In addition, the southern central Red Sea $\left(14-21^{\circ} \mathrm{N}\right)$ also experienced deeper MLDs during winter. The observed shallow MLD patches are not considered because the noise in the MLD $(\sim 44 \pm 14 \mathrm{~m})$ overlaps the mean MLD of the northern ( $\sim 53 \mathrm{~m})$ and southern $(\sim 48 \mathrm{~m})$ grids. The observed noise around $25^{\circ} \mathrm{N}$ is relatively small $(\sim 30 \pm 9 \mathrm{~m})$ compared to the difference in MLD values towards the northern $(\sim 70 \mathrm{~m})$ and southern $(\sim 50 \mathrm{~m})$ latitudes, and hence this is considered as a shallow MLD region.

During July to September, the region around $19^{\circ} \mathrm{N}$ experienced a deeper mixed layer in contrast with the general pattern of summer shoaling over the entire Red Sea. The deepening of the MLD begins in October throughout the Red Sea. The winter cooling and associated convection strengthens by December, with an average MLD>50 m, which intensifies by January and persists throughout February.

The mixed layer starts to shoal gradually by the end of February, and the MLDs of most areas decrease to $20 \pm 7 \mathrm{~m}$

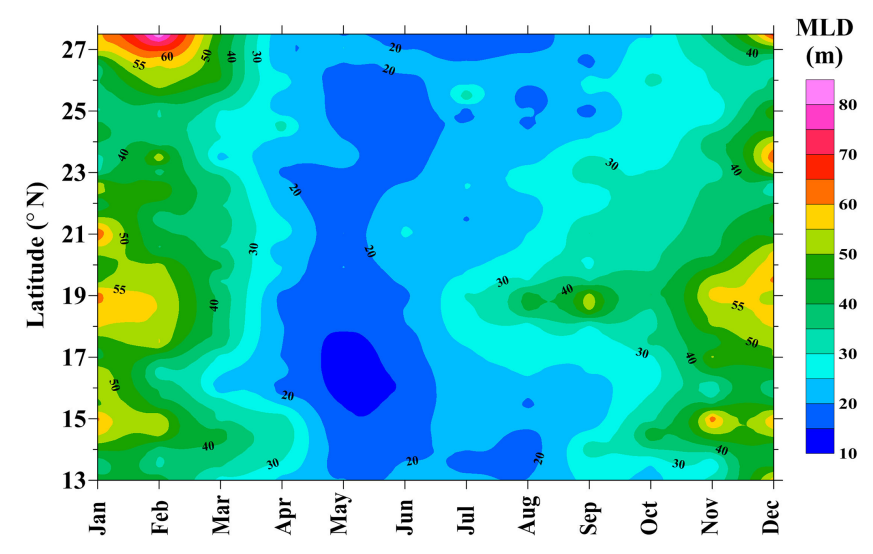

Figure 3. Hovmöller diagram of the MLD climatology along the axis of the Red Sea.

by April. Summer shoaling is comparatively stronger in the $15-18^{\circ} \mathrm{N}$ latitude band, and the detected mean MLD is $<15 \mathrm{~m}$. Individual observations revealed that many profiles have MLDs $<5 \mathrm{~m}$. In general, the shallow mixed layers are predominant from April to September, while this prevails until October in the far north. In the south-central Red Sea, the shallow mixed layer exists for only a short period from April to June.

\subsection{Major forces controlling the MLD variability}

MLD is directly influenced by changes in the net heat flux (NHF), freshwater flux $(E-P)$, and wind stress. The different terms that contribute to NHF are given in Fig. 4 for a sample year 2016 in the central Red Sea. On an annual average basis, the incoming shortwave radiation (SWR; $202 \mathrm{~W} \mathrm{~m}^{-2}$, positive downward) is mainly balanced by LHF (latent heat flux, $-126 \mathrm{~W} \mathrm{~m}^{-2}$ ) and LWR (long wave radiation, $-83 \mathrm{~W} \mathrm{~m}^{-2}$ ), while the SHF (sensible heat flux) is only $-4 \mathrm{~W} \mathrm{~m}^{-2}$. The net heat loss in the central Red Sea is $11 \mathrm{~W} \mathrm{~m}^{-2}$. Both the LHF and LWR are gradually increasing towards the northern Red Sea. The monthly climatologies of the NHF in the northern, central, and southern Red Sea are given in Fig. 5a. Heat loss rises above $200 \mathrm{~W} \mathrm{~m}^{-2}$ during December-January in the northern Red Sea, with a maximum of $\sim 250 \mathrm{~W} \mathrm{~m}^{-2}$ at the northern end of the sea in December. The annual mean of NHF is negative (heat loss) across the Red Sea, except for isolated locations in the southern Red Sea with trivial heat gain (figure not shown). The thermal components of the buoyancy forces calculated based on Eq. (1) show that the heat flux supports mixing through buoyancy loss in the northern and central Red Sea during the winter, while it opposes vertical mixing due to buoyancy gain during summer. In the southern Red Sea, the effect of heat flux is relatively weak.

The evaporation rate in the Red Sea gradually increases from south to north (Fig. 5b). The central and northern Red Sea have higher evaporation during the winter 


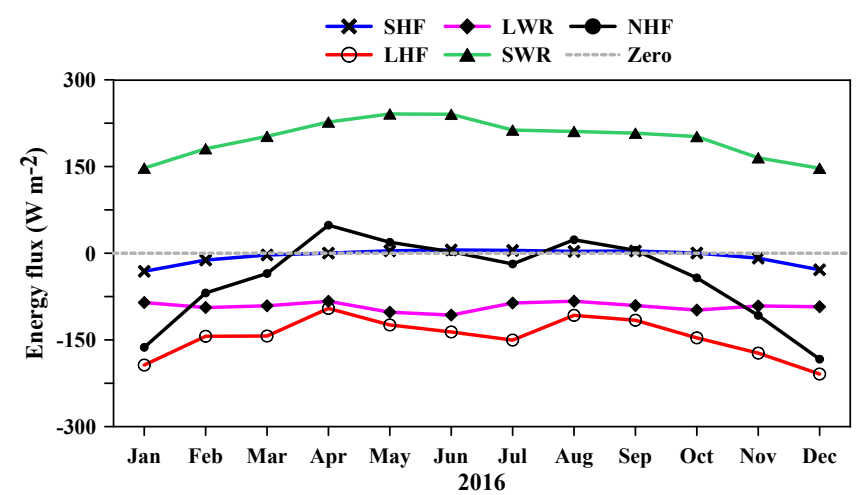

Figure 4. Time series of heat flux components (incoming shortwave radiation, SWR; longwave radiation, LWR; latent heat flux, LHF; sensible heat flux, SHF; and net heat flux, NHF) for the year 2016 in the central Red Sea.

$\left(\sim 6 \mathrm{~mm} \mathrm{day}^{-1}\right)$ and moderate evaporation $\left(\sim 3 \mathrm{~mm} \mathrm{day}^{-1}\right)$ during the summer. Evaporation shows weak seasonality in the southern Red Sea. Precipitation in the southern region is higher than that of the other areas of the Red Sea, with maximum rainfall during July-September (Fig. 5b). The changes in buoyancy forces corresponding to freshwater flux (haline component) are estimated based on Eq. (1), which shows that the changes support vertical mixing throughout the year and over the entire Red Sea. The thermal component is relatively higher than the haline component, and the net buoyancy flux follows a more or less similar pattern of thermal buoyancy flux all along the Red Sea (figure not shown). The observed variability of the above-discussed parameters is consistent with findings from earlier studies (Albarakati and Ahmad, 2013; Sofianos et al., 2002; Tragou et al., 1999).

The pattern of wind stress in the Red Sea is significantly different from the other parameters. The wind stress is strong during the winter, leading to enhanced turbulence and mixing, while it is weak during the summer, resulting in a shallower mixed layer (Fig. 5c, d). Apart from that, strong surface winds blow to the Red Sea through the Tokar Gap at approximately $19^{\circ} \mathrm{N}$ in July and August.

The correlations between MLDs and forcing factors are given in Fig. 6. The statistical significance of the correlation values are verified based on a $t$ test following Bretherton et al. (1999), and the estimated $p$ value, $t$ value, and the effective degree of freedom show that the correlation values are statistically significant at $95 \%$. The wind stress and $E-P$ are positively correlated with MLD, while the NHF is negatively correlated because as NHF (into the ocean) increases, MLD decreases. For simplicity of the figure (Fig. 6), the correlation values of all parameters are presented as positive. NHF and $E-P$ are well correlated (>0.8) with MLD in the central and northern Red Sea and weakly correlated in the south. Wind stress has a higher correlation $(>0.8)$ to the south, while it is relatively weakly correlated in the central

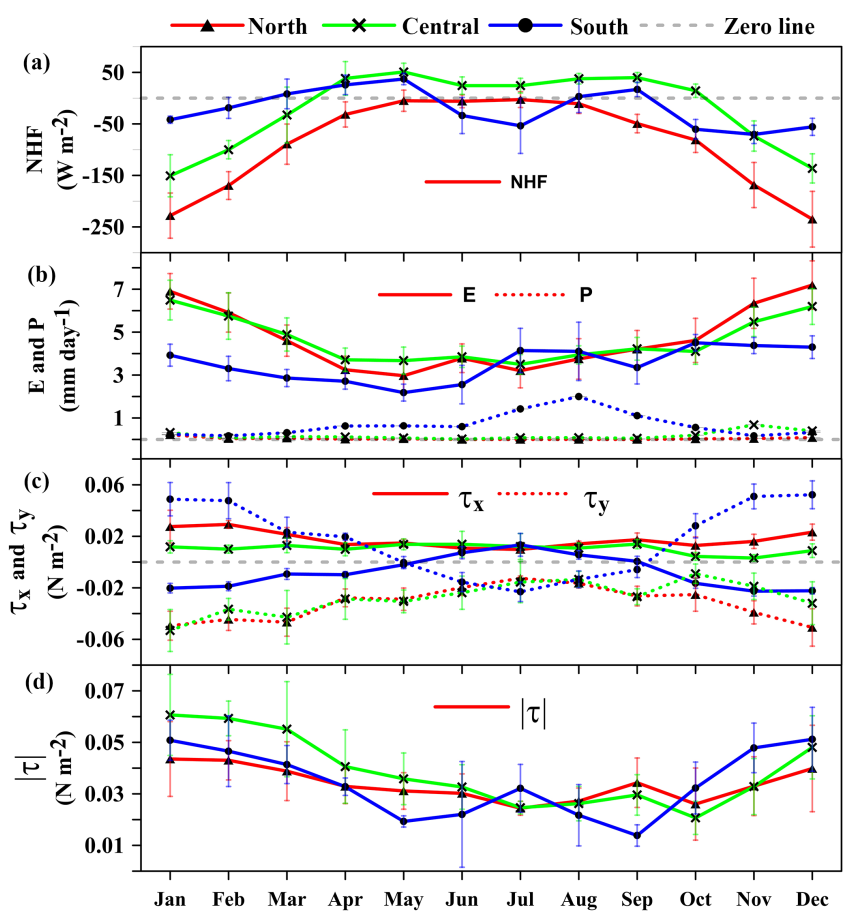

Figure 5. Monthly climatology of (a) NHF, (b) evaporation and precipitation, (c) eastward $\left(\tau_{x}\right)$ and northward $\left(\tau_{y}\right)$ component of wind stress, and (d) magnitude of the wind stress $(|\tau|)$. South, central, and north regions are represented by the changes at 14,21 , and $27^{\circ} \mathrm{N}$.

and northern Red Sea. Toward the northern end, the wind stress gradually achieves a higher correlation.

The results from Figs. 5 and 6 indicate that the MLD variability of the Red Sea is dominated by wind stress in the southern part; NHF (heat flux) and evaporation play a major role in the central region, while all three influence the northern region. Remarkably, for all the above-discussed parameters, coinciding drops are observed in the correlations at approximately $13.5,17.5,19,23$, and $26.5^{\circ} \mathrm{N}$, which indicates the impact of additional forces like eddies and currents in regulating the MLD variability of the region.

Earlier studies have proved that the upper ocean is efficiently re-stratified by ocean eddies, which may significantly change the MLD. The resultant effect of eddy is largely dependent on the eddy amplitude. The mixing intensity is largest at the center of the eddy and decays on average with increasing radial distance (Dewar, 1986; Fox-Kemper et al., 2008; Hausmann et al., 2017; Smith and Marshall, 2009). The observed results show that the mixing associated with eddies dominates over the existing effect of wind stress and heat flux. CE diminishes mixing through the upwelling of the subsurface water, while $\mathrm{AE}$ enhances mixing through the downwelling of the surface water (de Boyer Montegut et al., 2004; Chelton et al., 2004, 2011; Dewar, 1986; Hausmann et al., 2017). 
Table 1. The mean MLD in the north and south of the Tokar jet axis from July to October.

\begin{tabular}{lrr|rr|rr}
\hline \multirow{2}{*}{ 1-15 days of the month } & \multicolumn{2}{c|}{ Mean } & Standard deviation & Number of profiles \\
\cline { 2 - 7 } & North & South & North & South & North & South \\
\hline July (before) & 20 & 26 & 5 & 8 & 19 & 12 \\
August (during) & 24 & 38 & 8 & 17 & 27 & 24 \\
September (just after) & 30 & 52 & 11 & 14 & 27 & 27 \\
October (after 1 month) & 31 & 34 & 9 & 12 & 36 & 30 \\
\hline
\end{tabular}

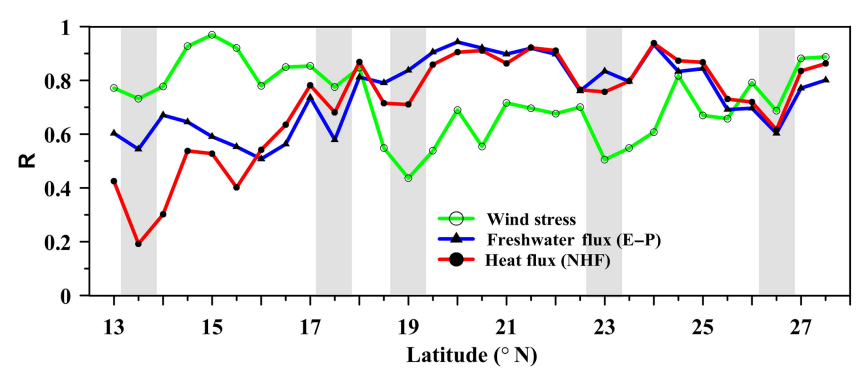

Figure 6. Correlation between major forces and MLD. Shaded regions represent locations of coinciding drops in correlation.

Satellite altimetry maps revealed the presence of multiple eddies in the Red Sea which are often confined to specific latitude bands (Clifford et al., 1997; Johns et al., 1999; Quadfasel and Baudner, 1993; Sofianos and Johns, 2007). Analyzing the SLA maps from 1992 to 2012, Zhan et al. (2014) reported the presence of multiple eddies with both polarities in the Red Sea. The number of identified eddies peaked at approximately 19.5 and $23.5^{\circ} \mathrm{N}$. The upwelling proxy constructed using MODIS SST in the northern Red Sea shows the presence of frequent upwelling events at approximately $26.5^{\circ} \mathrm{N}$ almost every year (Papadopoulos et al., 2015), indicating the presence of cyclonic eddy. The extent and time of the upwelling vary from year to year. In summary, a significantly large number of eddies are noticed around 19.5, 23.5, and $26.5^{\circ} \mathrm{N}$, which could be the possible reason for coinciding drops in the correlation around 19,23 , and $26.5^{\circ} \mathrm{N}$.

The Red Sea is very narrow at $13.5^{\circ} \mathrm{N}$. Moreover, complex dynamics occur in this region associated with surface and subsurface currents in the strait between the Red Sea and the Gulf of Aden. The complexity of this region prevents linking the MLD variability directly to atmospheric forcing or eddies. The region at approximately $17.5^{\circ} \mathrm{N}$ is between the two eddy-driven downwelling zones at approximately 15 and $19^{\circ} \mathrm{N}$ (Fig. 3). Mass conservation requires upwelling to replace the downwelling water. The MLD climatology shows shallow mixed layers throughout the year at $17.5^{\circ} \mathrm{N}$, which could be due to possible upwelling. Further investigation is required to unveil the dynamics associated with this region.
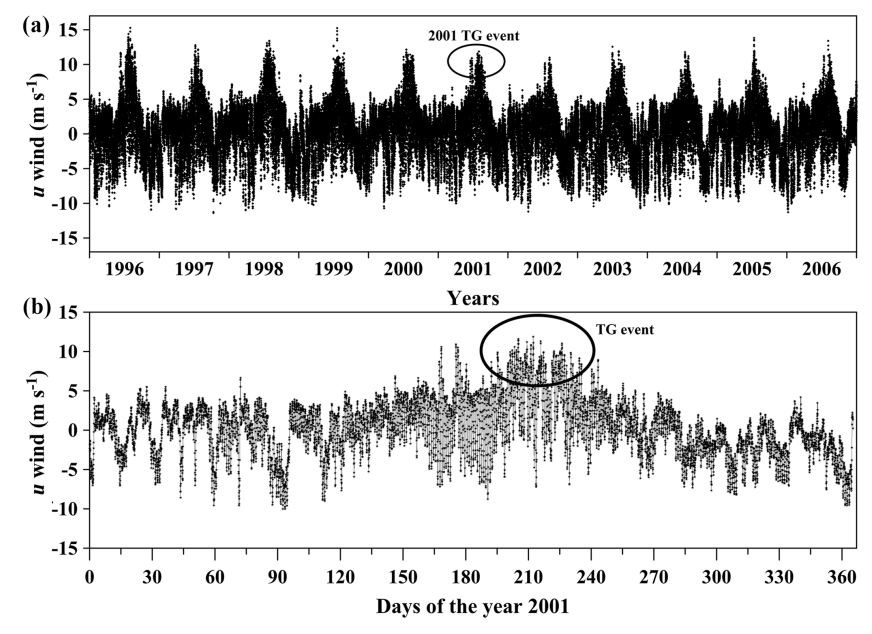

Figure 7. The $u$ component of the CFSR hourly surface wind near the Tokar region $\left(38.5^{\circ} \mathrm{E}, 18.5^{\circ} \mathrm{N}\right.$ ) (a) from 1996 to 2006 and (b) for the year 2001. The ellipse indicates the TG event in the year 2001.

\subsection{Influence of Tokar Gap winds during the summer}

The Tokar Gap is one of the largest gaps in the high orography located on the African coast of the Red Sea, near $19^{\circ} \mathrm{N}$. Strong winds are funneled to the Red Sea through this gap which last for a few days to weeks. Figure 7a shows the $u$ component of CFSR hourly surface wind at the Tokar region from 1996 to 2006. The figure shows that the strong wind events occur during summer every year, while the intensity and duration of the event vary from year to year. Tokar Gap winds frequently attain a speed of $15 \mathrm{~m} \mathrm{~s}^{-1}$. Previous research also shows similar results (Jiang et al., 2009; Ralston et al., 2013; Zhai and Bower, 2013). Zhai and Bower (2013) reported that wind speed may reach 20 to $25 \mathrm{~m} \mathrm{~s}^{-1}$ according to ship-based observations. Figure $7 \mathrm{~b}$ shows that the onset of the 2001 Tokar event was on 20 July and continued until 20 August, when the maximum wind speed occurred during this period compared to rest of the year. These strong winds generate strong turbulence in the surface water, which enhances vertical mixing.

The temperature and salinity profiles measured during summer 2001 (13-14 August 2001), which coincided with the Tokar event, are shown in Fig. 8a and b (Sofianos and 


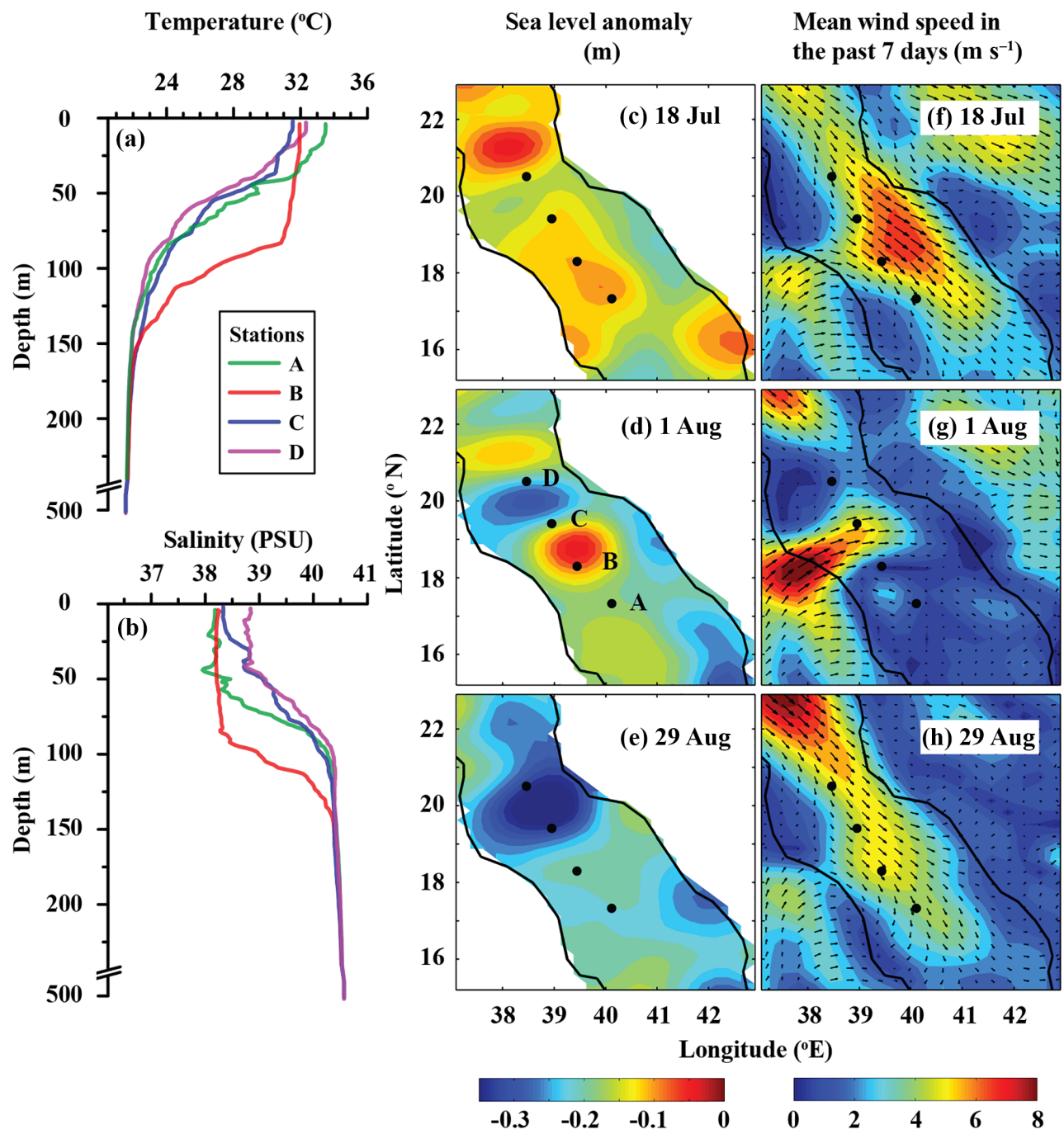

Figure 8. (a) The CTD-measured temperature and salinity profiles during 13-14 August 2001. (b) SLA maps and (c) wind speed and direction (averaged for the previous 1 week) in the Tokar region before, during, and after the Tokar event. The temperature and salinity profiles are received through personal communication from Sofianos and Johns (2007).

Johns, 2007; Zhai and Bower, 2013). The signature of the Tokar event is clearly visible in the satellite-derived SLA, with well-defined cyclonic and anticyclonic eddies to the north and south of the Tokar Gap, respectively (Fig. 8c-e). Both eddies have a basin-wide influence and radii between 70 and $80 \mathrm{~km}$. The corresponding wind speed pattern (averaged for the previous 7 days) is shown (Fig. $8 \mathrm{f}-\mathrm{h}$ ). The profiles to the north and south of the jet axis display a significant difference in MLD, with a deeper mixed layer in the south. Station A is far from both cyclonic and anticyclonic eddies and shows the expected MLD during this period. The presence of the anticyclonic eddy at station B enhances strong downwelling, extending the mixing to a depth of approximately $80 \mathrm{~m}$. It should be noted that the entire Red Sea basin is well stratified during this period, with MLDs ranging from 10 to $15 \mathrm{~m}$. Stations C and D are located at the edge of the cyclonic eddy, and both have a shallower thermocline and mixed layer.

The MLDs of all the available profiles in the Tokar region before, during, just after, and after a month of the Tokar event are plotted in Fig. 9 (profiles for the first 15 days of each month are displayed). The mean MLD, standard deviation, and number of profiles are given in Table 1. Before the Tokar event, the southern and northern sides of the Tokar axis (1819.5 and $19.5-21^{\circ} \mathrm{N}$, respectively) displayed similar mixed layers (Fig. 9a-c). During the Tokar event, the southern side experienced enhanced mixing, while the northern side shows a shallow mixed layer (Fig. 9d-f).

The anticyclonic part of the Tokar-induced eddies enhances downwelling and the associated deepening of the mixed layer along the southern side of the jet axis, while the cyclonic eddies generate upwelling and the associated shoal- 


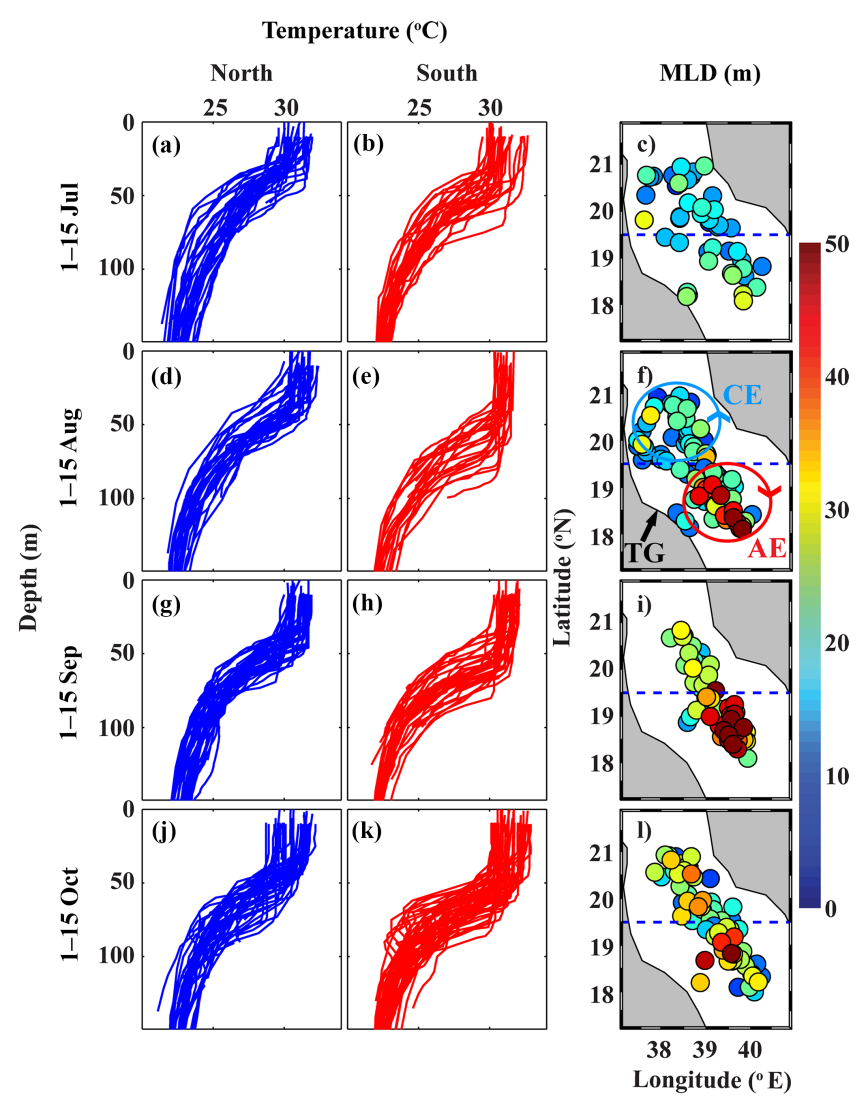

Figure 9. Temperature profiles from the north of the Tokar axis (left panel, blue curves), south of the Tokar axis (middle panel, red curves), and the corresponding MLD (right panel) during the first 15 days of each month from July to October. The dashed line passes through $19.5^{\circ} \mathrm{N}$, roughly separating the north and south of the Tokar axis. The MLD of each profile is represented by the filled colors. The blue and red circles in (f) schematically represent cyclonic and anticyclonic eddies during the Tokar event, respectively.

ing of the mixed layer along the northern side. The profiles in September (just after the Tokar event) show that the southern side is well mixed by the event, which leads to an average difference of $20 \mathrm{~m}$ in the MLDs between the two sides of the Tokar axis (Fig. 9g-i). The signature of the Tokar event in the MLDs (MLD difference between north and south of the jet axis) has disappeared by October (1 month after the Tokar event; Fig. 9j-1). The dominant effect of mountain gap winds on MLD changes has been reported in many studies globally, for instance in the Gulf of Tehuantepec in the eastern tropical Pacific (Gonzalez-Silvera et al., 2004; Stumpf, 1975) and Bora in the Mediterranean Sea (Grisogono and Belusic, 2009).

The mixing in the Tokar region during summer is the sum of the two mechanisms, the wind-induced turbulent mixing and the secondary circulation (eddies) induced by the wind. Both mechanisms act in the same direction on the southern side of the jet axis, resulting in enhanced mixing, while they act in the opposite direction on the northern side, leading to reduced mixing. Further studies are required for a proper quantification of the contribution of each mechanism. In summary, during the summer, the turbulence induced by strong wind and the impact of anticyclonic eddy enhance vertical mixing on the southern side of jet axis, while the windinduced mixing is diminished by the presence of cyclonic eddy on the northern side of the jet axis.

\section{Conclusions}

Detailed information on MLD variability is crucial for understanding the physical and biological processes in the ocean. The goals of this study were to produce a climatology record of MLD for the Red Sea and to investigate the role of major forces in MLD changes. With the help of in situ temperature profiles from CTD, XBT, MBT, and profiler float measurements, the MLD variability in the Red Sea has been explored for the first time and the MLD climatology is produced for every $0.5^{\circ}$ along the main axis. The climatology reasonably captured all the major features of MLD variability in the Red Sea. The present work provides a climatological mean of the MLD structure in the Red Sea and its seasonal variability. Influences of wind stress, heat flux, evaporation, and precipitation are explored. Further, the impact of the Tokar Gap jet stream winds, the eddies, and the upwelling events in the northern Red Sea are investigated.

A deep ventilation process associated with the winter cooling is observed across the entire Red Sea during the months of December to February (Fig. 3). Similarly, very shallow MLDs associated with increased shortwave radiation are detected all along the region from May to June. The climatological winter MLD ranges from $\sim 40$ to $85 \mathrm{~m}$ (in January). Similarly, the climatological summer MLD varies from 10 to $\sim 20 \mathrm{~m}$ (in June), which may reach $>40$ (in July). The mixed layer becomes deeper toward the north, even though the pattern is not linear with increasing latitude. The largest amplitude of variability is observed at the tip of the northern Red Sea, which is associated with strong deep convection during the winter and shoaling during the summer. The region at approximately $19^{\circ} \mathrm{N}$ experienced deeper MLD than is typical elsewhere in the Red Sea. This region experienced enhanced mixing during winter by surface cooling and during summer by both the Tokar Gap wind-induced turbulent mixing and the formation of the anticyclonic eddy. The deepest mixed layer is observed at the northern tip of the Red Sea during the winter, but the deep nature of the northern mixed layer is almost limited to the winter months.

Correlation analyses between MLD and forcing factors displayed the influence of major forces on MLD from north to south of the Red Sea. In general, the wind stress mainly controls the MLD variability in the southern part of the Red Sea, heat flux and evaporation dominate in the central region, and all three forces contribute in the northern region. Coin- 
ciding drops are observed in the correlations for all the selected forcing factors around the previously reported main eddy locations. In these locations, eddies override the controls of the other main forces, namely wind stress, heat flux, and freshwater flux. The quasi-permanent cyclonic gyre and upwelling in the northern Red Sea lead to the shoaling of the mixed layer at $\sim 26.5^{\circ} \mathrm{N}$ throughout almost the whole year.

The anticyclonic eddy induced by Tokar Gap winds and the wind-induced turbulent mixing together enhanced the deep convection and mixing along the southern side of the Tokar jet axis during the summer, while the wind-induced mixing is reduced by the cyclonic eddy. This leads to a deepening of the mixed layer to $>40 \mathrm{~m}$, while the MLDs in the rest of the Red Sea are $<20 \mathrm{~m}$. The effect of the Tokar event is seen in the profiles of late July to early August, which gradually disappeared by October. The frequent eddies associated with surface circulation and Tokar events have a strong impact on the MLD structure of the Red Sea.

Data availability. The climatology data produced in this paper are available from the repository Figshare (https://doi.org/10.6084/m9.figshare.5539852). The monthly mean values of heat fluxes and wind stress data are available from TropFlux (http://www.incois.gov.in/tropflux_ datasets/data/monthly/, 1 February 2017). The monthly mean values of evaporation are accessible from OAFlux (ftp: //ftp.whoi.edu/pub/science/oaflux/data_v3/monthly/evaporation/, 1 February 2017). The precipitation data are available from TRMM (https://pmm.nasa.gov/data-access/downloads/trmm, 1 February 2017).

\section{The Supplement related to this article is available online at https://doi.org/10.5194/os-14-563-2018-supplement.}

Author contributions. CPA, MAA, TMA, and AMA designed the work. CPA did the analysis. CPA, MAA, and TMA interpreted the results. CPA prepared the manuscript with significant contribution from all the authors.

Competing interests. The authors declare that they have no conflict of interest.

Acknowledgements. This project was funded by the Deanship of Scientific Research (DSR), King Abdulaziz University, under grant number 438/150/129. The authors therefore acknowledge the DSR's technical and financial support. The authors acknowledge TropFlux, OAFlux, TRMM, AVISO, CFSR, the World Ocean Database, and the CORIOLIS data center for making their data products publicly available. The authors also acknowledge the institutes that have provided CTD profiles from different cruises. The author CPA acknowledges the Deanship of Graduate Studies, King Abdulaziz University, Jeddah, for providing a PhD Fellowship.

Edited by: Piers Chapman

Reviewed by: two anonymous referees

\section{References}

Abdulla, C. P., Alsaafani, M. A., Alraddadi, T. M., and Albarakati, A. M.: Estimation of Mixed Layer Depth in the Gulf of Aden: A New Approach, PLoS One, 11, e0165136, https://doi.org/10.1371/journal.pone.0165136, 2016.

Aboobacker, V. M., Shanas, P. R., Alsaafani, M. A., and Albarakati, A. M.: Wave energy resource assessment for Red Sea, Renew. Energy, 114, 46-58, https://doi.org/10.1016/j.renene.2016.09.073, 2016.

Albarakati, A. M. and Ahmad, F.: Variation of the surface buoyancy flux in the Red Sea, Indian J. Mar. Sci., 42, 717-721, 2013.

Alsaafani, M. A. and Shenoi, S. S. C.: Seasonal cycle of hydrography in the Bab el Mandab region, southern Red Sea, J. Earth Syst. Sci., 113, 269-280, https://doi.org/10.1007/BF02716725, 2004.

Alsaafani, M. A. and Shenoi, S. S. C.: Water masses in the Gulf of Aden, J. Oceanogr., 63, 1-14, https://doi.org/10.1007/s10872007-0001-1, 2007.

Beal, L. M., Ffield, A., and Gordon, A. L.: Spreading of Red Sea overflow waters in the Indian Ocean, J. Geophys. Res., 105, 8549-8564, https://doi.org/10.1029/1999JC900306, 2000.

Bower, A. S. and Farrar, J. T.: Air-sea interaction and horizontal circulation in the Red Sea, in The Red Sea, 329-342, Springer, New York, 2015.

Boyer, T. P. and Levitus, S.: Quality control and processing of historical temperature, salinity, and oxygen data, NOAA Tech. Rep., NESDIS 81, 65, 1994.

de Boyer Montegut, C., Madec, G., Fischer, A. S., Lazar, A., and Iudicone, D.: Mixed layer depth over the global ocean: An examination of profile data and a profilebased climatology, J. Geophys. Res.-Oceans, 109, 1-20, https://doi.org/10.1029/2004JC002378, 2004.

Bretherton, C. S., Widmann, M., Dymnikov, V. P., Wallace, J. M., and Bladé, I.: The Effective Number of Spatial Degrees of Freedom of a Time-Varying Field, J. Clim., 12, 1990-2009, https://doi.org/10.1175/15200442(1999)012<1990:TENOSD>2.0.CO;2, 1999.

Carlson, D. F., Fredj, E., and Gildor, H.: The annual cycle of vertical mixing and restratification in the Northern Gulf of Eilat/Aqaba (Red Sea) based on high temporal and vertical resolution observations, Deep. Res. Part I, 84, 1-17, https://doi.org/10.1016/j.dsr.2013.10.004, 2014.

Chelton, D. B., Schlax, M. G., Freilich, M. H., and Milliff, R. F.: Satellite measurements reveal persistent small-scale features in ocean winds, Science, 303, 978-983, 2004.

Chelton, D. B., Schlax, M. G., and Samelson, R. M.: Global observations of nonlinear mesoscale eddies, Prog. Oceanogr., 91, 167-216, https://doi.org/10.1016/j.pocean.2011.01.002, 2011.

Chen, D., Busalacchi, A. J., and Rothstein, L. M.: The roles of vertical mixing, solar radiation, and wind stress in a model simulation of the sea surface temperature seasonal cy- 
cle in the tropical Pacific Ocean, J. Geophys. Res., 99, 20345, https://doi.org/10.1029/94JC01621, 1994.

Cheng, L., Zhu, J., Cowley, R., Boyer, T. P., and Wijffels, S.: Time, probe type, and temperature variable bias corrections to historical expendable bathythermograph observations, J. Atmos. Ocean. Technol., 31, 1793-1825, https://doi.org/10.1175/JTECH-D-1300197.1, 2014.

Clifford, M., Horton, C., Schmitz, J., and Kantha, L. H.: An oceanographic nowcast/forecast system for the Red Sea, J. Geophys. Res.-Oceans, 102, 25101-25122, https://doi.org/10.1029/97JC01919, 1997.

D’Ortenzio, F., Iudicone, D., de Boyer Montegut, C., Testor, P., Antoine, D., Marullo, S., Santoleri, R., and Madec, G.: Seasonal variability of the mixed layer depth in the Mediterranean Sea as derived from in situ profiles, Geophys. Res. Lett., 32, L12605, https://doi.org/10.1029/2005GL022463, 2005.

Dewar, W. K.: Mixed layers in Gulf Stream rings, Dyn. Atmos. Ocean., 10, 1-29, 1986.

Ducet, N., LaTraon, P. Y., and Reverdin, G.: Global highresolution mapping of ocean circulation from TOPEX/Poseidon and ERS-1 and -2, J. Geophys. Res.-Oceans, 105, 19477-19498, https://doi.org/10.1029/2000JC900063, 2000.

Fox-Kemper, B., Ferrari, R., and Hallberg, R.: Parameterization of Mixed Layer Eddies, Part I: Theory and Diagnosis, J. Phys. Oceanogr., 38, 1145-1165, https://doi.org/10.1175/2007JPO3792.1, 2008.

Gonzalez-Silvera, A., Santamaria-del-Angel, E., Millán-Nuñez, R., and Manzo-Monroy, H.: Satellite observations of mesoscale eddies in the Gulfs of Tehuantepec and Papagayo (Eastern Tropical Pacific), Deep Sea Res. Pt. II, 51, 587-600, https://doi.org/10.1016/j.dsr2.2004.05.019, 2004.

Grisogono, B. and Belusic, D.: A review of recent advances in understanding the meso- and microscale properties of the severe Bora wind, Tellus A, 61, 1-16, https://doi.org/10.1111/j.16000870.2008.00369.x, 2009.

Hausmann, U., McGillicuddy, D. J., and Marshall, J.: Observed mesoscale eddy signatures in Southern Ocean surface mixed-layer depth, J. Geophys. Res.-Oceans, 122, 617-635, https://doi.org/10.1002/2016JC012225, 2017.

Jiang, H., Farrar, J. T., Beardsley, R. C., Chen, R., and Chen, C.: Zonal surface wind jets across the Red Sea due to mountain gap forcing along both sides of the Red Sea, Geophys. Res. Lett., 36, 1-6, https://doi.org/10.1029/2009GL040008, 2009.

Johns, W. E., Jacobs, G. A., Kindle, J. C., Murray, S. P., and Carron, M.: Arabian marginal seas and gulfs, University of Miami RSMAS Technical Report, University of Miami, Floria, USA, 1999.

Kara, A. B., Rochford, P. A., and Hurlburt, H. E.: Mixed layer depth variability over the global ocean, J. Geophys. Res., 108, 3079, https://doi.org/10.1029/2000JC000736, 2003.

Keerthi, M. G., Dyn, C., Monte, C. D. B., Lengaigne, M., Vialard, J., Boyer Montégut, C., Muraleedharan, P. M., Dyn, C., Monte, C. D. B., Keerthi, M. G., Lengaigne, M., Vialard, J., Boyer Montégut, C., Muraleedharan, P. M., de Boyer Montégut, C., and Muraleedharan, P. M.: Interannual variability of the Tropical Indian Ocean mixed layer depth, Clim. Dynam., 40, 743-759, https://doi.org/10.1007/s00382-012-1295-2, 2012.

Keerthi, M. G., Lengaigne, M., Drushka, K., Vialard, J., Montegut, C. D. B., Pous, S., Levy, M., and Muraleedharan,
P. M.: Intraseasonal variability of mixed layer depth in the tropical Indian Ocean, Clim. Dynam., 46, 2633-2655, https://doi.org/10.1007/s00382-015-2721-z, 2016.

LaTraon, P. Y. and Dibarboure, G.: Mesoscale Mapping Capabilities of Multiple-Satellite Altimeter Missions, J. Atmos. Ocean. Technol., 16, 1208-1223, https://doi.org/10.1175/15200426(1999)016<1208:MMCOMS>2.0.CO;2, 1999.

Lorbacher, K., Dommenget, D., Niiler, P. P., and Köhl, A.: Ocean mixed layer depth: A subsurface proxy of oceanatmosphere variability, J. Geophys. Res.-Oceans, 111, 1-22, https://doi.org/10.1029/2003JC002157, 2006.

Papadopoulos, V. P., Zhan, P., Sofianos, S. S., Raitsos, D. E., Qurban, M., Abualnaja, Y., Bower, A. S., Kontoyiannis, H., Pavlidou, A., Asharaf, T. T. M., Zarokanellos, N., and Hoteit, I.: Factors governing the deep ventilation of the Red Sea, J. Geophys. Res.-Oceans, 120, 7493-7505, https://doi.org/10.1002/2015JC010996, 2015.

Polovina, J., Mitchum, G. T., and Evans, T.: Decadal and basinscale variation in mixed layer depth and the impact on biological production in the Central and North Pacific, 1960-1988, Deep Sea Res., 42, 1701-1716, 1995.

Praveen Kumar, B., Vialard, J., Lengaigne, M., Murty, V. S. N., and McPhaden, M. J.: TropFlux: air-sea fluxes for the global tropical oceans - description and evaluation, Clim. Dynam., 38, 15211543, https://doi.org/10.1007/s00382-011-1115-0, 2012.

Praveen Kumar, B., Vialard, J., Lengaigne, M., Murty, V. S. N., McPhaden, M. J., Cronin, M. F., Pinsard, F., and Gopala Reddy, K.: TropFlux wind stresses over the tropical oceans: evaluation and comparison with other products, Clim. Dynam., 40, 20492071, https://doi.org/10.1007/s00382-012-1455-4, 2013.

Quadfasel, D. and Baudner, H.: Gyre-scale circulation cells in the red-sea, Oceanol. Acta, 16, 221-229, 1993.

Ralston, D. K., Jiang, H., and Farrar, J. T.: Waves in the Red Sea: Response to monsoonal and mountain gap winds, Cont. Shelf Res., 65, 1-13, https://doi.org/10.1016/j.csr.2013.05.017, 2013.

Saha, S., Moorthi, S., Pan, H. L., Wu, X., Wang, J., Nadiga, S., Tripp, P., Kistler, R., Woollen, J., Behringer, D., Liu, H., Stokes, D., Grumbine, R., Gayno, G., Wang, J., Hou, Y. T., Chuang, H. Y., Juang, H. M. H., Sela, J., Iredell, M., Treadon, R., Kleist, D., Van Delst, P., Keyser, D., Derber, J., Ek, M., Meng, J., Wei, H., Yang, R., Lord, S., Van Den Dool, H., Kumar, A., Wang, W., Long, C., Chelliah, M., Xue, Y., Huang, B., Schemm, J. K., Ebisuzaki, W., Lin, R., Xie, P., Chen, M., Zhou, S., Higgins, W., Zou, C. Z., Liu, Q., Chen, Y., Han, Y., Cucurull, L., Reynolds, R. W., Rutledge, G., and Goldberg, M.: The NCEP climate forecast system reanalysis, Bull. Am. Meteorol. Soc., 91, 1015-1057, https://doi.org/10.1175/2010BAMS3001.1, 2010.

Shanas, P. R., Aboobacker, V. M., Albarakati, A. M. A., and Zubier, K. M.: Climate driven variability of windwaves in the Red Sea, Ocean Model., 119, 105-117, https://doi.org/10.1016/j.ocemod.2017.10.001, 2017.

Smith, K. S. and Marshall, J.: Evidence for Enhanced Eddy Mixing at Middepth in the Southern Ocean, J. Phys. Oceanogr., 39, 5069, https://doi.org/10.1175/2008JPO3880.1, 2009.

Sofianos, S. S. and Johns, W. E.: An Oceanic General Circulation Model (OGCM) investigation of the Red Sea circulation, 1. Exchange between the Red Sea and the Indian Ocean, J. Geophys. Res., 107, 3196, https://doi.org/10.1029/2001JC001184, 2002. 
Sofianos, S. S. and Johns, W. E.: Observations of the summer Red Sea circulation, J. Geophys. Res.-Oceans, 112, 1-20, https://doi.org/10.1029/2006JC003886, 2007.

Sofianos, S. S., Johns, W. E., and Murray, S. P.: Heat and freshwater budgets in the Red Sea from direct observations at Bab el Mandeb, Deep. Res. Part II, 49, 1323-1340, https://doi.org/10.1016/S0967-0645(01)00164-3, 2002.

Stumpf, H. G.: Satellite Detection of Upwelling in the Gulf of Tehuantepec, Mexico, J. Phys. Oceanogr., 5, 383-388, https://doi.org/10.1175/15200485(1975)005<0383:SDOUIT>2.0.CO;2, 1975.

Sutton, P. J., Worcester, P. F., Masters, G., Cornuelle, B. D., and Lynch, J. F.: Ocean mixed layers and acoustic pulse propagation in the Greenland Sea, J. Acoust. Soc. Am., 94, 1517-1526, https://doi.org/10.1121/1.408130, 2014.

Tragou, E., Garrett, C., Outerbridge, R., and Gilman, C.: The Heat and Freshwater Budgets of the Red Sea, J. Phys. Oceanogr., 29, 2504-2522, https://doi.org/10.1175/15200485(1999)029<2504:THAFBO>2.0.CO;2, 1999.

Turner, J. S.: Buoyancy Effects in Fluids, Cambridge University Press, Cambridge, 1973.
Yao, F., Hoteit, I., Pratt, L. J., Bower, A. S., Zhai, P., Köhl, A., and Gopalakrishnan, G.: Seasonal overturning circulation in the Red Sea: 1. Model validation and summer circulation, J. Geophys. Res.-Oceans, 119, 2238-2262, https://doi.org/10.1002/2013JC009004, 2014a.

Yao, F., Hoteit, I., Pratt, L. J., Bower, A. S., Köhl, A., Gopalakrishnan, G., and Rivas, D.: Seasonal overturning circulation in the Red Sea: 2. Winter circulation, J. Geophys. Res.-Oceans, 119, 2263-2289, https://doi.org/10.1002/2013JC009331, 2014b.

Zeng, L. and Wang, D.: Seasonal variations in the barrier layer in the South China Sea: characteristics, mechanisms and impact of warming, Clim. Dynam., 48, 1911-1930, https://doi.org/10.1007/s00382-016-3182-8, 2017.

Zhai, P. and Bower, A. S.: The response of the Red Sea to a strong wind jet near the Tokar Gap in summer, J. Geophys. Res.-Oceans, 118, 422-434, https://doi.org/10.1029/2012JC008444, 2013.

Zhan, P., Subramanian, A. C., Yao, F., and Hoteit, I.: Eddies in the Red Sea: A statistical and dynamical study, J. Geophys. Res.-Oceans, 119, 3909-3925, https://doi.org/10.1002/2013JC009563, 2014. 